\title{
PABRE-Proj: Applying Patterns in Requirements Elicitation
}

\author{
Cristina Palomares, Carme Quer, Xavier Franch \\ Software Engineering for Information Systems (GESSI) \\ Universitat Politècnica de Catalunya (UPC), Barcelona, (Catalonia, Spain) \\ \{cpalomares, cquer, franch\}@essi.upc.edu
}

\begin{abstract}
Software requirement patterns have been proposed as a type of artifact for fostering requirements reuse. In this paper, we present PABRE-Proj, a tool aimed at supporting requirements elicitation and specification.

Index Terms - Requirement patterns; requirements reuse; callfor-tender processes
\end{abstract}

\section{INTRODUCTION}

The PABRE framework proposes the use of Software Requirement Patterns (SRP) as a means to capture and use requirements knowledge in the context of IT procurement projects. It currently embraces: a catalogue of 29 NonFunctional SRP [1] and 37 Non-Technical SRP [2]; a metamodel that describes the structure of patterns and the catalogue [3]; a method for guiding the use of the catalogue in the requirements engineering stage [4]; and the PABRE software system as technological support. All these assets were obtained through our collaboration with the SSI group at the Public Research Centre Henri Tudor at Luxembourg.

The PABRE system is composed of the tools PABRE-Man and PABRE-Proj. PABRE-Man is the pattern management tool. Its goal is to facilitate the definition of SRP and their organization into an SRP catalogue. Their users are Requirements Engineering Experts who decide to add new SRP, who analyze the SRP usage data to evolve the catalogue, and who maintain the classification schemas used to organize the SRP in the catalogue.

PABRE-Proj's goal is to facilitate the definition of the requirements for a certain IT project. Their users are Requirements Analysts (RA). During the requirements elicitation of a specific project, the tool helps recommending, using the SRP catalogue, the requirements to add to the Software Requirements Specification (SRS) document of the project. Once the elicitation process finishes, the tool also allows to generate automatically a Call-for-Tenders document to be sent to potential providers and a report with the data of use of SRP.

PABRE-Man has already been presented at RE 2011 [5]. This paper focuses then on PABRE-Proj.

\section{PABRE-PROJ USE DURING REQUIREMENTS ELICITATION}

The main steps of use of PABRE-Proj during an elicitation project are: browsing the SRP catalogue and adding requirements. We will illustrate these steps focusing on the use of the Supplier Economic Information SRP (see Fig. 1) as example and its classification in the PABRE catalogue.

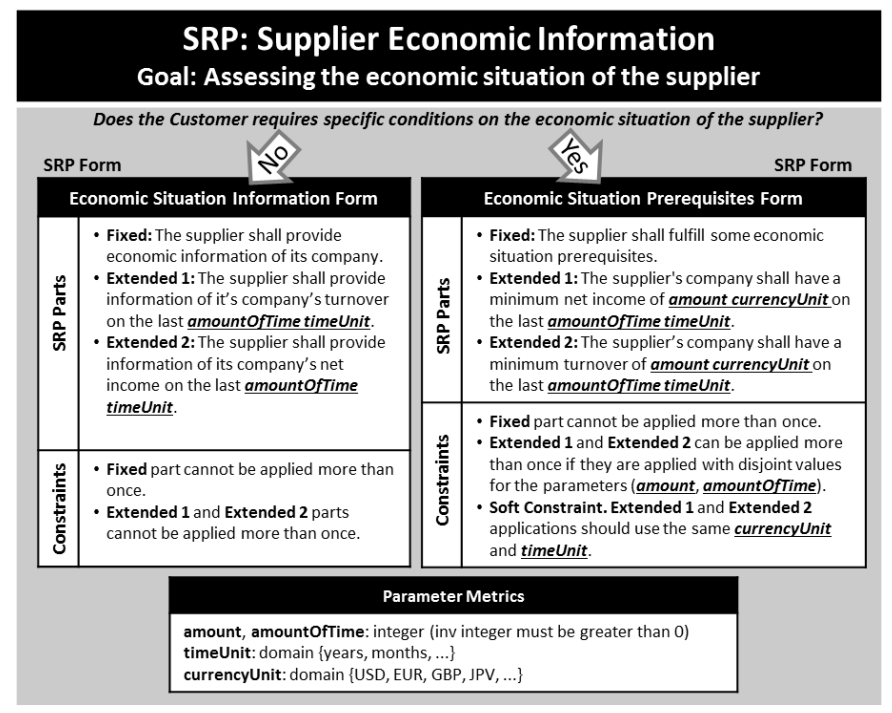

Figure 1. Supplier Economic Information Pattern

\section{A. Browsing the SRP Catalogue}

The aim of this step is to identify SRP that may be interesting for the Customer needs. In our example, the RA may conduct this identification in different ways.

First, the Customer may explain that $\mathrm{s} / \mathrm{he}$ is interested in a requirement with a similar goal than the one of the SRP, which is Assessing the economic situation of the supplier in our case.

Second, the RA may propose the SRP to the Customer because $\mathrm{s} /$ he considers that may be relevant to the project; this may be inferred because just before a requirement related to this SRP was defined. Relationships are stored in two different ways in the PABRE catalogue: as dependence relationships and as classification relationships. The example SRP is not involved in any dependence relationship, but its classification in the catalogue may allow the RA to propose this SRP if for instance the Supplier Workforce SRP has been used just before in the project, since both SRP appear in the same category in the classification schema (see Fig. 2).

The PABRE system allows to have different classification schemas, and each RA may choose the one s/he prefers. The classification schema in Fig. 2 is an extension of the ISO 91261 quality model.

It is worth to remark that in both cases, the SRP goal is the key knowledge asset to decide the adequacy of an SRP pattern in the given project. 


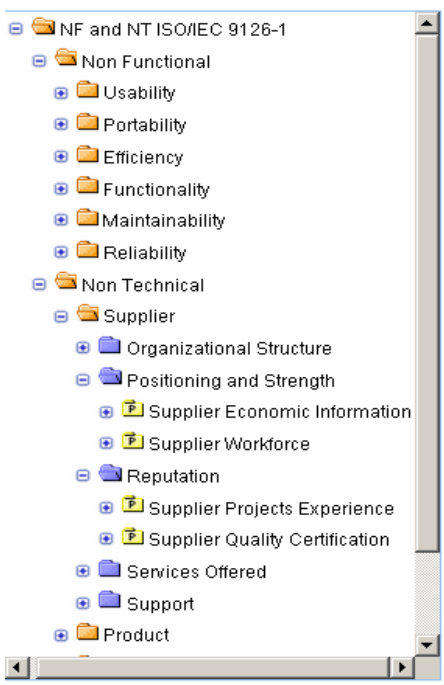

Figure 2. Browsing the SRP Catalogue

\section{B. Adding Requirements}

Assuming that the customer is interested in achieving the goal of the Supplier Economic Information SRP, the following tasks show the scenario of application of this SRP in order to derive the appropriate requirements (see scenario $\mathrm{M}$ in Fig. 3 ).

1) Choose Form to Apply. The RA explains the different SRP Forms to achieve the goal. In our pattern example there are two Forms (see Fig. 1) depending on whether the customer is interested to fix prerequisites on the supplier economic situation or $\mathrm{s} / \mathrm{he}$ is just interested in obtaining economic data to assess that situation. If there is not any Form that suits the idea of the customer (e.g., s/he may be interested in achieving the goal by having access to the result of an audit made by an external party), the RA directly defines new requirements related to the SRP goal (see alternative scenario A in Fig. 3).

2) Choose Parts to Apply. Assuming that the customer chooses an existing Form, the RA describes him/her the requi-

\begin{tabular}{|c|c|c|}
\hline \multicolumn{3}{|c|}{ Scenario M } \\
\hline $\begin{array}{l}\text { (1) } \\
\text { Choose } \\
\text { Form to } \\
\text { Apply }\end{array}$ & $\begin{array}{l}\text { (A) } \\
\text { Suitable Form }\end{array}$ & $\begin{array}{l}\text { A1: The supplier shall provide the last audit done to } \\
\text { its company. } \\
\text { A2: The company audit shall be made during the last } \\
2 \text { years. } \\
\text { A3: The audit shall be conducted by an external } \\
\text { organization. }\end{array}$ \\
\hline $\begin{array}{l}\text { (2) } \\
\text { Choose } \\
\text { Parts to } \\
\text { Apply }\end{array}$ & (B) & $\begin{array}{l}\text { B1: The supplier shall fulfill some economic situation } \\
\text { prerequisites. } \\
\text { B2: The supplier's company shall have a minimum } \\
\text { net income of } 10 \mathrm{M} \text { euros on the last } 2 \text { years. } \\
\text { B3: The supplier's company shall have a deficit } \\
\text { below the } 30 \mathrm{M} \text { euros on the last } 2 \text { years. }\end{array}$ \\
\hline $\begin{array}{l}(3) \\
\text { State } \\
\text { Parameter } \\
\text { values }\end{array}$ & $\begin{array}{l}\text { (C) } \\
\text { Small } \\
\text { changes }\end{array}$ & $\begin{array}{l}\text { C1: The supplier shall fulfill some economic situation } \\
\text { prerequisites. } \\
\text { C2: The supplier's company shall have a net income } \\
\text { above } 10 \mathrm{M} \text { euros on the last } 3 \text { years. } \\
\text { C3: The supplier's company shall have a turnover } \\
\text { above } 40 \mathrm{M} \text { euros on the last } 3 \text { years. }\end{array}$ \\
\hline \multicolumn{3}{|c|}{$\begin{array}{l}\text { M1: The supplier shall fulfill some economic situation prerequisites. } \\
\text { M2: The supplier's company shall have a minimum net income of } \mathbf{M} \text { euros } \\
\text { on the last } \mathbf{2} \text { years. } \\
\text { M3: The supplier's company shall have a minimum turnover of } 2.5 \mathrm{M} \text { euros } \\
\text { on the last } 2 \text { years. }\end{array}$} \\
\hline
\end{tabular}

Figure 3. Adding Requirements rements that would derive from the SRP Parts of that Form. In the example SRP, assuming the Form on the right is selected (see Fig. 1), these requirements allow the RA to state prerequisites to fix the turnover and the net income of the supplier. If the customer wants to put prerequisites on other aspects not included in the SRP, for instance on the deficit of the supplier organization, new requirements related to the SRP Form will be defined (see alternative scenario B in Fig. 3). 3.

3) State Parameter Values. Assuming that the customer chooses one Form and one or more Parts of an SRP to apply, the parameters in those Parts must be filled (marked in bold and underlined in the SRP Parts of Fig. 1). In the example SRP, if the customer is interested in a minimum net income of $1 \mathrm{M}$ euros and a minimum turnover of $2.5 \mathrm{M}$ euros for the last 2 years, the Fixed and both Extended Parts of the SRP need to be applied (see scenario M). If the customer does not like the writing of some Part it can be changed during its application (see alternative scenario $\mathrm{C}$ in Fig. 3).

In case that no SRP exists in the catalogue appropriate for a customer need, new requirements are defined. Considering our current SRP catalogue, this would occur if the customer is interested in stating requirements on the supplier market share.

\section{FINAL REMARKS}

The main benefits that the use of an SRP catalogue and our tools may provide to RA are: 1) More effective requirement elicitation (requirements are not built from scratch; a process guides RA by giving recommendations, suggesting information, etc.); and 2) Improved quality and wording of requirements documents (by the uniform style of SRP).

Currently, PABRE-Proj is used in software procurement internal trial projects conducted by TUDOR to identify usability aspects that we are implementing to improve the tool. In this context, PABRE-Proj interoperates with the OPAL tool [6] developed by TUDOR. Trials of PABRE-Proj and the current SRP catalogue are open to industry provided an agreement among the involved parts (more information can be found [7]).

\section{ACKNOWLEDGMENT}

This work has been partially funded by the Spanish project TIN-2010-19130-C02-01.

\section{REFERENCES}

[1] S. Renault, O. Mendez-Bonilla, X. Franch, C. Quer: "A Pattern-based Method for building Requirements Documents in Call-for-tender Processes". IJCSA 6(5), 2009.

[2] C. Palomares, C. Quer, X. Franch, C. Guerlain, S. Renault: "A Catalogue of Non-Technical Requirement Patterns". RePa 2012.

[3] X. Franch, C. Palomares, C. Quer, S. Renault, F. De Lazzer: "A Metamodel for Software Requirement Patterns". REFSQ 2010.

[4] X. Franch, C. Quer, S.Renault, C.Guerlain, C.Palomares. "Constructing and Using Software Requirements Patterns". Book chapter in Managing Requirements Knowledge, Springer 2013.

[5] C. Palomares, C.Quer, X.Franch: "PABRE-Man: Management of a Requirement Patterns Catalogue". Tool Demo at RE 2011.

[6] M. Krystkowiak, V. Bétry, E. Dubois. "Efficient COTS Selection with OPAL Tool”. MPEC 2004.

[7] PABRE web page. http://www.upc.edu/gessi/PABRE/Use.html 